\title{
Estado nutricional de bananeiras tipo Prata sob diferentes sistemas de irrigação
}

\author{
Sérgio Luiz Rodrigues Donato(1), Alex Aguiar Lédo(1), Marlon Cristian Toledo Pereira(2), \\ Eugênio Ferreira Coelho ${ }^{(3)}$, Carlos Elízio Cotrim ${ }^{(1)}$ e Maurício Antônio Coelho Filho(3)
}

\begin{abstract}
(1)Instituto Federal de Educação Ciência e Tecnologia Baiano, Campus Guanambi, Caixa Postal 009, Distrito de Ceraima, CEP 46430-000 Guanambi, BA. E-mail: sergiodonatoeaf@yahoo.com.br, alexcaetite@yahoo.com.br, c-cotrim@hotmail.com ${ }^{(2)}$ Universidade Estadual de Montes Claros, Campus Janaúba, Centro de Ciências Exatas e Tecnológicas, Departamento de Ciências Agrárias, Avenida Reinaldo Viana, oㅡ 2.630, Caixa Postal, 91, Bico da Pedra, CEP 39440-000 Janaúba, MG. E-mail: marlon.pereira@unimontes.br (3)Embrapa Mandioca e Fruticultura Tropical, Caixa Postal 007, Rua Embrapa, s/no, CEP 44380-000 Cruz das Almas, BA. E-mail: eugenio@cnpmf.embrapa.br, macoelho@cnpmf.embrapa.br
\end{abstract}

Resumo - O objetivo deste trabalho foi avaliar os teores foliares de nutrientes e a produtividade de bananeiras tipo Prata, submetidas a diferentes sistemas de irrigação, durante o primeiro ciclo de produção. Adotou-se o delineamento experimental em blocos ao acaso, com seis tratamentos dispostos em esquema fatorial 3x2: três sistemas de irrigação (aspersão convencional, microaspersão e gotejamento); e dois genótipos (Prata-Anã e seu híbrido PA42-44). Utilizaram-se quatro repetições, no espaçamento de 3,0x2,5 m. Procedeu-se às avaliações aos 90, 180 e 360 dias após o plantio. Os genótipos e os sistemas de irrigação apresentaram interações significativas quanto aos teores foliares de $\mathrm{B}$ e $\mathrm{Cu}$, aos 180 dias após o plantio; e os genótipos diferiram entre si quanto aos teores de $\mathrm{N}, \mathrm{P}, \mathrm{K}, \mathrm{Ca}, \mathrm{Mg}, \mathrm{Cu}$ e $\mathrm{Mn}$, independentemente dos sistemas de irrigação. Os teores foliares dos nutrientes ocorreram em níveis adequados ou acima deles. Os menores teores foliares de micronutrientes ocorrem sob gotejamento. Os genótipos apresentam produtividade similar nos diferentes sistemas de irrigação.

Termos para indexação: Musa, avaliação nutricional, genótipos, rendimento.

\section{Nutritional status of Prata type bananas under different irrigation systems}

\begin{abstract}
The objective of this work was to evaluate nutrient leaf contents and the productivity of 'Prata-Anã' banana submitted to different irrigation systems, during the first production cycle. The experimental design was in randomized blocks, with six treatments in $3 \times 2$ factorial arrangement: three irrigation systems (conventional sprinkler, microsprinkler and drip); and two genotypes (Prata-Anã and its hybrid PA42-44). Four replicates were used in a $3.0 \times 2.5-\mathrm{m}$ spacing. The evaluations were done at 90, 180 and 360 days after planting. The genotypes and the irrigation systems showed significant interaction for leaf contents of $\mathrm{B}$ and $\mathrm{Cu}$, at 180 days after planting; and the genotypes differed from each other for leaf contents of $\mathrm{N}, \mathrm{P}, \mathrm{K}, \mathrm{Ca}, \mathrm{Mg}, \mathrm{Cu}$ and $\mathrm{Mn}$, independently of the irrigation system used. Nutrient leaf contents occurred in sufficient levels or above them. The lowest micronutrient leaf contents occur under drip irrigation. The genotypes have similar yield under the different irrigation systems.
\end{abstract}

Index terms: Musa, nutritional evaluation, genotypes, yield.

\section{Introdução}

A bananeira (Musa spp.), planta originária do Continente Asiático, é cultivada no Brasil em ecossistemas variados e em diferentes níveis tecnológicos. Cultivos de bananeira sob diferentes sistemas de irrigação podem diferir quanto à produtividade, ainda que se utilizem as mesmas cultivares e condições de cultivo. Isto decorre de diferenças na aplicação da água relacionadas à uniformidade de distribuição, à área e ao volume molhados, à intensidade e frequência de aplicação, o que pode alterar a distribuição espacial do sistema radicular, os atributos químicos do solo e o fluxo difusivo de nutrientes e, portanto, afetar os teores de nutrientes na planta.

Essas considerações, válidas para qualquer cultivo, têm especial relevância para a bananeira, que possui baixa capacidade de troca de cátions do sistema radicular, equivalente a $23 \pm 4 \mathrm{cmol}_{\mathrm{c}} \mathrm{kg}^{-1}$ de raízes para os eixos radiculares principais e $34 \pm 3 \mathrm{cmol}_{\mathrm{c}} \mathrm{kg}^{-1}$ para as raízes laterais (Rufyikiri et al., 2002), e tem alta exigência de nutrientes, o que demanda uma cinética 
de disponibilização correspondente à cinética de exigência da planta (Martin-Prével, 1984).

Entre os sistemas de irrigação mais utilizados no cultivo da bananeira, a aspersão convencional subcopa e a microaspersão possibilitam maior área molhada e são menos sujeitos a problemas decorrentes da qualidade da água, do que a irrigação por gotejamento ou por sulco. Entretanto, a uniformidade de distribuição de água sobre o solo, nos sistemas aspersão e microaspersão, é mais influenciada pelas condições climáticas, em particular o vento, e pelos pseudocaules das bananeiras que interceptam os jatos d'água (Costa et al., 2008). Na irrigação por gotejamento, a água é aplicada diretamente sobre a região radicular, em pequena intensidade e alta frequência, para manter a umidade no valor próximo ao da capacidade de campo. Isto propicia elevada eficiência de aplicação de água e melhores condições de umidade na zona radicular, nos primeiros cinco meses de idade da cultura, pois, nesta fase, as raízes encontram-se próximas do pseudocaule (Costa et al., 2008). Porém, a partir desse período, a extensão do bulbo molhado poderá limitar a expansão horizontal do sistema radicular da bananeira. Silva et al. (2009) constataram que o aumento no número de gotejadores por planta promove maior exploração do solo pelo sistema radicular da bananeira, maior absorção de água e menores perdas por percolação, o que resulta em maior eficiência da irrigação.

A análise química do tecido foliar é importante para avaliar o estado nutricional das plantas, em complemento à análise química do solo e à diagnose visual, e reflete a dinâmica de nutrientes no sistema solo-planta. No entanto, é necessário que se atente para a época e a posição das folhas amostradas (Silva \& Borges, 2008). A interpretação dos resultados da análise foliar baseia-se na comparação com padrões nutricionais, e pode ser realizada com o emprego de diversas técnicas, como a faixa de suficiência (Cantarutti et al., 2007). As faixas de suficiência para cultivares de diferentes subgrupos de bananeiras encontram-se estabelecidas, inclusive com refinamento específico para 'Prata-Comum' (Prezotti, 1992), 'Prata-Anã' (Silva et al., 2002) e 'Pacovan' (Borges \& Caldas, 2004).

O conhecimento do estado nutricional da cultura, resultante da combinação entre cultivares e sistemas de irrigação, pode fornecer subsídios para a identificação de carências ou excessos, antes da expressão na forma de sintomas. Isto possibilita a correção de desordens preliminarmente à ocorrência de prejuízos à produtividade.

O objetivo deste trabalho foi avaliar os teores foliares de nutrientes e a produtividade em bananeiras tipo 'Prata', submetidas a diferentes sistemas de irrigação, durante o primeiro ciclo de produção.

\section{Material e Métodos}

O experimento foi implantado em Latossolo Vermelho-Amarelo distrófico típico, com horizonte A fraco, textura média, fase caatinga hipoxerófila, relevo plano a suave-ondulado, cuja caracterização física e química, antes da implantação da cultura, encontra-se na Tabela 1 . O solo foi cultivado com olerícolas durante seis anos consecutivos, com adição de adubos orgânicos. A área experimental localizase no Instituto Federal de Educação, Ciência e Tecnologia Baiano, Campus Guanambi, Município de Guanambi, BA, a $14^{\circ} 13^{\prime} 30^{\prime \prime} \mathrm{S}, 42^{\circ} 46^{\prime} 53^{\prime \prime} \mathrm{W}$ e à altitude de $525 \mathrm{~m}$. A precipitação média anual é de $664 \mathrm{~mm}$, e a temperatura média anual de $26^{\circ} \mathrm{C}$.

Tabela 1. Características químicas e físicas do solo da área experimental, antes do plantio, nas profundidades 0-20 e $20-40 \mathrm{~cm}$.

\begin{tabular}{lcc}
\hline Característica & $0-20 \mathrm{~cm}$ & $20-40 \mathrm{~cm}$ \\
\hline $\mathrm{pH}$ em água & 7,20 & 6,95 \\
Matéria orgânica $\left(\mathrm{g} \mathrm{kg}^{-1}\right)$ & 7,0 & 1,5 \\
$\mathrm{P}\left(\mathrm{mg} \mathrm{dm}^{-3}\right)$ & 91,30 & 26,10 \\
$\mathrm{~K}\left(\mathrm{mg} \mathrm{dm}^{-3}\right)$ & 193,50 & 183,50 \\
$\mathrm{Na}\left(\mathrm{cmol}_{\mathrm{c}} \mathrm{dm}^{-3}\right)$ & 0,20 & 0,20 \\
$\mathrm{Ca}\left(\mathrm{cmol}_{\mathrm{c}} \mathrm{dm}^{-3}\right)$ & 3,40 & 2,20 \\
$\mathrm{Mg}\left(\mathrm{cmol}_{\mathrm{c}} \mathrm{dm}^{-3}\right)$ & 1,25 & 1,00 \\
$\mathrm{Al}\left(\mathrm{cmol}_{\mathrm{c}} \mathrm{dm}^{-3}\right)$ & 0,00 & 0,00 \\
$\mathrm{H}+\mathrm{Al}_{\left(\mathrm{cmol}_{\mathrm{c}} \mathrm{dm}^{-3}\right)}$ & 0,95 & 0,95 \\
$\mathrm{SB}\left(\mathrm{cmol}_{\mathrm{c}} \mathrm{dm}^{-3}\right)$ & 5,35 & 3,90 \\
$\mathrm{t}\left(\mathrm{cmol}_{\mathrm{c}} \mathrm{dm}^{-3}\right)$ & 5,35 & 3,90 \\
$\mathrm{~T}\left(\mathrm{cmol}_{\mathrm{c} \mathrm{dm}} \mathrm{dm}^{-3}\right)$ & 6,25 & 4,75 \\
$\mathrm{~V}(\%)$ & 85,50 & 81,00 \\
$\mathrm{~B}\left(\mathrm{mg} \mathrm{dm}^{-3}\right)$ & 0,55 & 0,55 \\
$\mathrm{Cu}\left(\mathrm{mg} \mathrm{dm}^{-3}\right)$ & 0,70 & 0,30 \\
Fe $\left(\mathrm{mg} \mathrm{dm}^{-3}\right)$ & 16,15 & 14,65 \\
Mn $\left(\mathrm{mg} \mathrm{dm}^{-3}\right)$ & 36,30 & 16,45 \\
$\mathrm{Zn}\left(\mathrm{mg} \mathrm{dm}^{-3}\right)$ & 5,25 & 1,20 \\
Prem $\left(\mathrm{mg} \mathrm{L}^{-1}\right)$ & 12,00 & 9,30 \\
Condutividade elétrica $\left(\mathrm{ds} \mathrm{m}{ }^{-1}\right)$ & 1,20 & 1,15 \\
Areia $\left(\mathrm{g} \mathrm{kg}^{-1}\right)$ & 650 & 670 \\
Silte $\left(\mathrm{g} \mathrm{kg}^{-1}\right)$ & 105 & 60 \\
Argila $\left(\mathrm{g} \mathrm{kg}^{-1}\right)$ & 245 & 270 \\
\hline
\end{tabular}


Utilizou-se o espaçamento de 3,0x2,5 m e mudas micropropagadas, cedidas pela Embrapa Mandioca e Fruticultura Tropical. A implantação e os tratos culturais seguiram as recomendações para a cultura, conforme Rodrigues et al. (2008).

$\mathrm{Na}$ cova de plantio, foram feitas adubações química $\mathrm{P}$ e $\mathrm{N}$ na forma de fosfato monoamônio, $50 \mathrm{~g}$ por cova de $\mathrm{P}_{2} \mathrm{O}_{5}$ e $10 \mathrm{~g}$ de $\mathrm{N}$, e micronutrientes na forma de FTE (B, 2\%; Cu, 0,8\%; Mn, 2\%; Mo, 0,1\% e Zn, 8\%), 30 g por cova - e orgânica - $18 \mathrm{~L}$ de esterco de bovino por cova, correspondente a $6,84 \mathrm{~kg}$ por cova. A cada dois meses, foram realizadas adubações orgânicas em cobertura, num total de seis aplicações, na dose final de $6,84 \mathrm{~kg}$ por família, também com esterco bovino que apresentava a seguinte composição: macronutrientes - $\mathrm{Ca}, \mathrm{Mg}, \mathrm{K}, \mathrm{P}, \mathrm{N}$ e $\mathrm{S}$ com 1,7, 0,2, 2,5, 4,7, 5,2 e $2,3 \mathrm{~g} \mathrm{~kg}^{-1}$, respectivamente - , e micronutrientes $-\mathrm{B}, \mathrm{Cu}$, $\mathrm{Zn}, \mathrm{Mn}$ e Fe com 2, 1, 45,2, 200,5, 391,8 e 1.932,4 $\mathrm{mg} \mathrm{kg}^{-1}$, respectivamente.

As adubações minerais em cobertura foram constituídas por: 6,6 e 20 g por família de $\mathrm{N}$, respectivamente aos 30,60 e 90 dias após o plantio, com sulfato de amônio; 44 e 13 g por família de $\mathrm{N}$ e $\mathrm{K}_{2} \mathrm{O}$, respectivamente, com nitrato de potássio; e 25 g por família de $\mathrm{Mg}$, com sulfato de magnésio. As adubações em cobertura foram realizadas a lanço, e as doses estabelecidas conforme Silva et al. (1999) e Silva \& Borges (2008). As aplicações de B e Zn foram efetuadas no rizoma, na muda desbastada, aos 180 dias, antes das amostragens foliares, com 1,7 g de B, por família, na forma de ácido bórico, e $4 \mathrm{~g}$ de $\mathrm{Zn}$, por família, na forma de sulfato de zinco. Aplicaram-se, ainda, de forma fracionada, aos 300 dias e 330 dias, as doses totais de $0,65 \mathrm{~g}$ de $\mathrm{Cu}$, por família, na forma de sulfato de cobre; $1,7 \mathrm{~g}$ de $\mathrm{B}$, por família, com ácido bórico; e $4 \mathrm{~g}$ de $\mathrm{Zn}$, por família, na forma de sulfato de zinco (Rodrigues et al., 2007).

A fonte de água utilizada foi a de poço tubular, classificada como $\mathrm{C}_{3} \mathrm{~S}_{1}$ - água com alta salinidade e baixa concentração de sódio. A análise química da água apresentou $\mathrm{pH}$ 6,6; condutividade elétrica de $0,82 \mathrm{dS} \mathrm{m}^{-1}$; e concentrações, em $\mathrm{mg} \mathrm{L}^{-1}$, de: $\mathrm{Ca}^{2+}$, 3,53; $\mathrm{Mg}^{2+}, 2,23 ; \mathrm{K}^{+}, 0,15 ; \mathrm{Na}^{+}, 3,48 ; \mathrm{Cl}^{-}, 5,20$; $\mathrm{CO}_{3}^{2-}, 0 ; \mathrm{HCO}_{3}^{-}, 4,00$. No manejo da irrigação dos diferentes sistemas, adotou-se a lâmina de 5,04 mm por dia, em média. As lâminas aplicadas variaram ao longo do experimento, de acordo com as necessidades hídricas da cultura (Coelho et al., 2001), tendo-se estimado a evapotranspiração de referência (ETo) conforme Penman-Monteith. Os elementos meteorológicos usados nesse modelo - temperatura do ar $\left({ }^{\circ} \mathrm{C}\right)$, umidade relativa do ar $(\%)$, velocidade de vento $\left(\mathrm{m} \mathrm{s}^{-1}\right)$ e radiação solar $\left(\mathrm{MJ} \mathrm{m} \mathrm{m}^{-2}\right.$ por dia $\left.{ }^{1}\right)$ - foram coletados de uma estação meteorológica automática instalada na área. Nos cálculos, foram considerados também os atributos físico-hídricos do solo, determinados por análises laboratoriais, e as características dos sistemas de irrigação. $\mathrm{Na}$ fase de florescimento, foram aplicadas lâminas líquidas em quantidades ligeiramente inferiores às necessidades hídricas da cultura, por problemas operacionais de abastecimento d'água.

Utilizou-se o delineamento experimental de blocos ao acaso, com seis tratamentos, dispostos em esquema fatorial $3 \times 2$, com quatro repetições. Os três sistemas de irrigação avaliados foram: aspersão convencional subcopa, microaspersão e gotejamento. Os dois genótipos avaliados foram: 'Prata-Anã', triplóide $\mathrm{AAB}$, suscetível às sigatokas amarela e negra e ao mal-do-Panamá; e seu híbrido PA42-44, tetraplóide $\mathrm{AAAB}$, resistente à sigatoka-amarela e ao mal-do-Panamá, desenvolvido pela Embrapa Mandioca e Fruticultura Tropical. As parcelas experimentais úteis foram constituídas por seis plantas em fileira, com bordadura completa.

As características dos sistemas de irrigação convencional foram: irrigação em subcopa, com aspersores setoriais Naandan, modelo 427 1/2" (NaaDan Indústria e Comércio de Equipamentos para Irrigação Ltda., Leme, Brasil) macho, com vazão $1.500 \mathrm{~L}$ por hora, com bocal de $3,2 \mathrm{~mm}$, no espaçamento de $12 \mathrm{~m}$ entre linhas laterais e $12 \mathrm{~m}$ entre aspersores; microaspersão, com emissores Netafim, modelo autocompensante (Netafim Israel, Kibutz Hatzerim, Israel), de vazão $70 \mathrm{~L}$ por hora, diâmetro molhado de $6 \mathrm{~m}$, com bocal verde de $1,33 \mathrm{~mm}$, espaçamento de $6 \mathrm{~m}$ entre laterais e $5 \mathrm{~m}$ entre emissores; gotejamento com uma lateral por fileira de planta, com emissores sobrelinha modelo Catif (Plastro Brasil Sistemas de Irrigação, Uberlândia, Brasil), com vazão de 2,3 L por hora, e espaçamento entre laterais de $3 \mathrm{~m}$ e entre emissores de $0,30 \mathrm{~m}$.

As amostragens de folhas foram realizadas durante o primeiro ciclo de produção, aos 90 dias, na fase de crescimento vegetativo inicial, 180 dias, no período do florescimento, e aos 360 dias após o plantio das 
mudas, no período da colheita. Nas repetições de cada tratamento, nas três épocas citadas, coletaramse amostras simples de folha das seis plantas úteis de cada parcela, para compor a amostra composta (Silva et al., 2002). De cada amostra simples, foram retirados de 10 a $15 \mathrm{~cm}$ da parte interna mediana do limbo da terceira folha, sem a nervura central. As amostras compostas de cada repetição foram colocadas em sacos de papel, etiquetadas e enviadas ao laboratório para análise. A amostra internacional de referência (AIR) refere-se à terceira folha, a contar do ápice, com a inflorescência no estádio em que todas as pencas femininas encontram-se descobertas, sem brácteas, e com, no máximo, três pencas de flores masculinas (Martin-Prével, 1977). As amostragens feitas aos 90 e 360 dias não coincidiram com o estádio de florescimento, assim, em acordo com argumento de Martin-Prével (1984), adotaram-se alguns cuidados para a amostragem foliar, de forma a possibilitar as comparações com o padrão: as folhas amostradas não foram removidas da planta, mas delas foi retirada apenas a parte mediana central do limbo sem a nervura central; aos 90 dias de idade, foi amostrada a terceira folha, quando esta atingiu o máximo comprimento (Malburg, 1988); aos 180 dias de idade, foi coletada a folha três, conforme AIR; aos 360 dias de idade, na época da colheita, foi amostrada a folha três, tendose deslocado a posição de amostragem para a região imediatamente próxima de onde foi retirada a amostra na época do florescimento.

Nas amostras foliares, determinaram-se os teores de $\mathrm{N}, \mathrm{P}, \mathrm{K}, \mathrm{Ca}, \mathrm{Mg}$ e $\mathrm{S}\left(\mathrm{dag} \mathrm{kg}^{-1}\right)$, e de B, Cu, Fe, Mn e $\mathrm{Zn}\left(\mathrm{mg} \mathrm{kg}^{-1}\right)$, de acordo com Malavolta et al. (1997): $\mathrm{N}$, digestão sulfúrica com o método Kjeldahl; $\mathrm{P}, \mathrm{K}, \mathrm{S}$, $\mathrm{Ca}, \mathrm{Mg}, \mathrm{Cu}, \mathrm{Fe}, \mathrm{Mn}, \mathrm{Zn}$, e Na, digestão nítrico-perclórica; e $\mathrm{B}$, digestão via seca. As determinações analíticas foram realizadas no Laboratório de Solos da Empresa de Pesquisa Agropecuária de Minas Gerais, Unidade Regional Norte de Minas.

A produtividade foi estimada a partir de dados de massa de cada cacho, das seis plantas úteis de cada parcela. Os cachos foram colhidos observando um diâmetro mínimo de $32 \mathrm{~mm}$ no fruto central da fileira externa de frutos da segunda penca, no estádio de cor da casca totalmente verde.

Os dados dos teores de nutrientes na folha e de produtividade foram submetidos à análise de variância, as interações significativas foram desdobradas, e as médias foram comparadas pelo teste de Tukey, a 5\% de probabilidade. Nos casos em que não ocorreu interação, foram analisados os efeitos dos fatores isolados. Adicionalmente, procederam-se às interpretações dos valores dos teores foliares, para diagnóstico do estado nutricional da cultura, pela técnica dos intervalos ou faixas de suficiência, com base nos padrões estabelecidos por Silva et al. (2002), para a cultivar Prata-Anã, no norte de Minas Gerais.

\section{Resultados e Discussão}

Interações significativas entre genótipos e sistemas de irrigação foram registradas somente quanto aos teores foliares de $\mathrm{B}$ e $\mathrm{Cu}$, avaliados aos 180 dias após o plantio (Tabela 2). 'Prata-Anã' e PA42-44 diferiram significativamente entre si, sob o sistema de irrigação por gotejamento, quanto aos teores foliares de $\mathrm{B}$ e de $\mathrm{Cu}$, com maiores valores no híbrido. Borges et al. (2006) também observaram maiores teores de $\mathrm{B}$ e $\mathrm{Cu}$ na folha, no híbrido BRS Fhia-18, em comparação ao seu genitor, a 'Prata-Anã'. Isso, provavelmente, está relacionado à maior eficiência de absorção desses nutrientes em híbridos tetraplóides (Faria, 1997).

Em 'Prata-Anã', os teores foliares de $\mathrm{B}$ e $\mathrm{Cu}$ foram estatisticamente similares entre os sistemas de irrigação (Tabela 2). Em PA42-44, os teores foliares de B foram maiores no sistema sob gotejamento, comparado aos demais sistemas, e os teores de $\mathrm{Cu}$ foram maiores sob gotejamento do que sob aspersão.

Os maiores valores de $\mathrm{B}$ e $\mathrm{Cu}$, registrados sob gotejamento aos 180 dias, para o híbrido (Tabela 2), podem ser consequência das melhores condições de umidade na zona radicular, proporcionadas por esse sistema de irrigação, que teriam aumentado o

Tabela 2. Teores foliares médios de boro e cobre $\left(\mathrm{mg} \mathrm{kg}^{-1}\right)$, avaliados aos 180 dias após o plantio, nos genótipos de bananeira 'Prata-Anã' e 'PA42-44', submetidos aos sistemas de irrigação por aspersão convencional, microaspersão e gotejamento $^{(1)}$.

\begin{tabular}{lccccc}
\hline Irrigação & \multicolumn{2}{c}{ Boro } & & \multicolumn{2}{c}{ Cobre } \\
\cline { 2 - 3 } \cline { 5 - 6 } & 'Prata-Anã' & 'PA42-44' & & Prata-Anã' & 'PA42-44' \\
\hline Aspersão & $22,75 \mathrm{aA}$ & $17,67 \mathrm{aB}$ & & $7,21 \mathrm{aA}$ & $6,49 \mathrm{aB}$ \\
Microaspersão & $24,16 \mathrm{aA}$ & $17,87 \mathrm{aB}$ & & $6,76 \mathrm{aA}$ & $7,37 \mathrm{aAB}$ \\
Gotejamento & $20,81 \mathrm{bA}$ & $32,98 \mathrm{aA}$ & & $6,18 \mathrm{bA}$ & $8,61 \mathrm{aA}$ \\
\hline CV $(\%)$ & \multicolumn{2}{c}{30,00} & \multicolumn{2}{c}{15,91} \\
\hline
\end{tabular}

${ }^{(1)}$ Médias seguidas por letras iguais, minúsculas nas linhas e maiúsculas nas colunas, não diferem entre si pelo teste de Tukey, a 5\% de probabilidade. 
fluxo difusivo de nutrientes. Isto é particularmente importante nos primeiros cinco meses de idade da cultura, quando as raízes encontram-se próximas ao pseudocaule (Costa et al., 2008).

Os teores foliares de $\mathrm{B}$ e $\mathrm{Cu}$ observados estão dentro da faixa de suficiência nutricional para 'Prata-Anã', preconizada por Silva et al. (2002), com exceção dos teores de B no híbrido PA42-44, que estiveram acima da faixa. Damatto Junior et al. (2006) avaliaram o estado nutricional da bananeira 'Prata-Anã', cultivada com diferentes doses de composto orgânico no primeiro ciclo de produção, e obtiveram teores foliares de $\mathrm{B}$ de $54 \mathrm{mg} \mathrm{kg}^{-1}$, no florescimento, e $36 \mathrm{mg} \mathrm{kg}^{-1}$, na colheita, superiores aos observados no presente trabalho aos 180 dias. Também Silva \& Rodrigues (2001), em trabalho de levantamento nutricional de bananais da Região Norte de Minas Gerais, com predomínio da cultivar Prata-Anã, encontraram teores de B da ordem de $55,9 \mathrm{mg} \mathrm{kg}^{-1}$, e justificaram os resultados pelas adubações excessivas desse micronutriente, efetuada pelos produtores da Região.

Diferenças significativas nos teores foliares dos macronutrientes foram identificadas (Tabela 3) entre sistemas de irrigação, independentemente dos genótipos, para $\mathrm{N}$ aos 180 dias e Ca aos 90 dias após o plantio; e entre genótipos, independentemente dos sistemas de irrigação, para $\mathrm{N}$ aos 90 dias, $\mathrm{P}$ aos 360 dias, $\mathrm{K}$ aos 180 e 360 dias, $\mathrm{Ca}$ aos 90 dias, e para $\mathrm{Mg}$ nas três épocas de avaliação. A menor ocorrência de diferenças significativas entre sistemas de irrigação, provavelmente, está relacionada ao fato de a lâmina de água aplicada ter sido a mesma, nos três sistemas de irrigação. O maior número de diferenças significativas entre os genótipos está relacionado às diferenças na eficiência de absorção de nutrientes decorrente da variação genética (Faria, 1997; Borges et al., 2006), apesar de, no presente trabalho, terem sido avaliadas genitora e progênie. Borges et al. (2006) compararam os teores foliares de 24 genótipos, de diferentes grupos genômicos de bananeira, e observaram diferenças significativas no primeiro ciclo de produção, quanto a $\mathrm{N}, \mathrm{K}, \mathrm{Ca}, \mathrm{Mg}$ e $\mathrm{S}$ e, no segundo ciclo, para $\mathrm{K}, \mathrm{Ca}$, $\mathrm{Mg}$ e $\mathrm{S}$, inclusive entre genótipos do mesmo grupo genômico.

Quanto às diferenças observadas entre os sistemas de irrigação, para os teores de $\mathrm{N}$ aos 180 dias, observou-se que o sistema de irrigação por gotejamento proporcionou menores valores do que o sistema por microaspersão (Tabela 3). Os teores foliares de $\mathrm{N}$ enquadraramse acima da faixa de suficiência, nas três épocas de

Tabela 3. Teores foliares médios de macronutrientes (dag $\mathrm{kg}^{-1}$ ), avaliados aos 90,180 e 360 dias após o plantio, nos genótipos de bananeira 'Prata-Anã' e 'PA42-44', submetidos aos sistemas de irrigação por aspersão convencional, microaspersão e gotejamento $^{(1)}$.

\begin{tabular}{|c|c|c|c|c|c|c|c|}
\hline \multirow[t]{2}{*}{ Macronutriente } & \multirow[t]{2}{*}{ Dias } & \multicolumn{3}{|c|}{ Sistema de irrigação } & \multicolumn{2}{|c|}{ Genótipo } & \multirow[t]{2}{*}{ CV $(\%)$} \\
\hline & & Aspersão & Microaspersão & Gotejamento & 'Prata-Anã' & 'PA42-44' & \\
\hline \multirow{3}{*}{ Nitrogênio } & 90 & $3,50 \mathrm{a}$ & $3,64 \mathrm{a}$ & $3,59 \mathrm{a}$ & $3,65 \mathrm{a}$ & $3,46 b$ & 4,33 \\
\hline & 180 & $3,08 \mathrm{ab}$ & $3,14 \mathrm{a}$ & $2,89 b$ & $3,10 \mathrm{a}$ & $2,97 \mathrm{a}$ & 5,89 \\
\hline & 360 & $3,25 \mathrm{a}$ & $3,14 \mathrm{a}$ & $3,11 \mathrm{a}$ & $3,14 \mathrm{a}$ & $3,20 \mathrm{a}$ & 9,23 \\
\hline \multirow{3}{*}{ Fósforo } & 90 & $0,25 \mathrm{a}$ & $0,25 \mathrm{a}$ & $0,26 a$ & $0,24 a$ & $0,26 a$ & 13,79 \\
\hline & 180 & $0,23 \mathrm{a}$ & $0,23 \mathrm{a}$ & $0,22 \mathrm{a}$ & $0,22 \mathrm{a}$ & $0,24 \mathrm{a}$ & 8,66 \\
\hline & 360 & $0,21 \mathrm{a}$ & $0,21 \mathrm{a}$ & $0,20 \mathrm{a}$ & $0,20 \mathrm{~b}$ & $0,22 \mathrm{a}$ & 7,82 \\
\hline \multirow{3}{*}{ Potássio } & 90 & $4,65 a$ & $4,63 a$ & $4,84 \mathrm{a}$ & $4,37 \mathrm{a}$ & $4,92 \mathrm{a}$ & 13,14 \\
\hline & 180 & $3,45 \mathrm{a}$ & $3,41 \mathrm{a}$ & $3,69 \mathrm{a}$ & $3,35 b$ & $3,68 \mathrm{a}$ & 7,05 \\
\hline & 360 & $3,53 \mathrm{a}$ & $3,55 \mathrm{a}$ & $3,45 \mathrm{a}$ & $3,28 \mathrm{~b}$ & $3,74 \mathrm{a}$ & 10,65 \\
\hline \multirow{3}{*}{ Cálcio } & 90 & $0,46 b$ & $0,61 \mathrm{a}$ & $0,57 \mathrm{ab}$ & $0,59 a$ & $0,50 \mathrm{~b}$ & 17,58 \\
\hline & 180 & $0,64 \mathrm{a}$ & $0,59 \mathrm{a}$ & $0,60 \mathrm{a}$ & $0,61 \mathrm{a}$ & $0,62 \mathrm{a}$ & 20,60 \\
\hline & 360 & $0,98 \mathrm{a}$ & $0,85 \mathrm{a}$ & $1,00 \mathrm{a}$ & $0,94 \mathrm{a}$ & $0,83 \mathrm{a}$ & 28,68 \\
\hline \multirow{3}{*}{ Magnésio } & 90 & $0,40 \mathrm{a}$ & $0,43 a$ & $0,41 \mathrm{a}$ & $0,43 \mathrm{a}$ & $0,37 b$ & 14,25 \\
\hline & 180 & $0,38 \mathrm{a}$ & $0,38 \mathrm{a}$ & $0,38 \mathrm{a}$ & $0,40 \mathrm{a}$ & $0,36 b$ & 8,60 \\
\hline & 360 & $0,31 \mathrm{a}$ & $0,38 \mathrm{a}$ & $0,34 \mathrm{a}$ & $0,45 \mathrm{a}$ & $0,37 b$ & 14,80 \\
\hline \multirow{3}{*}{ Enxofre } & 90 & $0,30 \mathrm{a}$ & $0,32 \mathrm{a}$ & $0,31 \mathrm{a}$ & $0,31 \mathrm{a}$ & $0,29 a$ & 20,68 \\
\hline & 180 & $0,27 \mathrm{a}$ & $0,26 \mathrm{a}$ & $0,25 \mathrm{a}$ & $0,26 \mathrm{a}$ & $0,27 \mathrm{a}$ & 12,25 \\
\hline & 360 & $0,27 \mathrm{a}$ & $0,28 \mathrm{a}$ & $0,28 \mathrm{a}$ & $0,28 \mathrm{a}$ & $0,26 \mathrm{a}$ & 11,78 \\
\hline
\end{tabular}

\footnotetext{
(1) Médias seguidas por letras iguais nas linhas, para sistemas de irrigação e para genótipos, não diferem entre si, pelo teste de Tukey, a 5\% de probabilidade.
} 
avaliação, em todos os sistemas de irrigação, exceto no gotejamento aos 180 dias, que apresentou valores dentro da faixa. Silva \& Carvalho (2005) constataram, pelo método DRIS, excesso de $\mathrm{N}$ em $13 \%$ dos bananais de 'Prata-Anã', no norte de Minas Gerais.

Os sistemas de microaspersão e aspersão possibilitam maior área molhada (Costa et al., 2008) e, provavelmente, maior decomposição de adubos orgânicos e liberação de nutrientes, além de aumento do fluxo difusivo de nutrientes. As similaridades constatadas entre os sistemas de irrigação aos 90 e 360 dias após o plantio ocorreram, provavelmente, em razão das contribuições do $\mathrm{N}$ aplicado na cova e da maior disponibilidade de água, em área total, decorrente do período chuvoso, respectivamente.

O sistema de irrigação por aspersão convencional proporcionou os menores teores de $\mathrm{Ca}$ aos 90 dias (Tabela 3). Aos 90 e 180 dias, observaram-se teores foliares de $\mathrm{Ca}$ dentro da faixa adequada, em todos os sistemas de irrigação e, aos 360 dias (período chuvoso), valores acima da faixa. $\mathrm{O} \mathrm{Ca}$, assim como o N, encontra-se em maior concentração na solução do solo e apresenta baixa energia de ligação à fase sólida do solo. Portanto, esses nutrientes são transportados preferencialmente por fluxo de massa, de acordo com o fluxo transpiracional da planta. Assim, condições que maximizam ou minimizam a transpiração interferem diretamente na absorção desses nutrientes (Novais et al., 2007). Teores foliares de Ca superiores à faixa adequada também foram observados por Damatto Junior et al. (2006). Borges et al. (2006) observaram teores acima da faixa adequada em híbridos da 'Prata-Anã', no primeiro ciclo, e em 'Prata-Anã' no primeiro e no segundo ciclos. Silva \& Carvalho (2005) encontraram teores excessivos de Ca em 28\% dos bananais do Norte de Minas Gerais, pelo método DRIS, e justificaram que $50 \%$ da área selecionada era irrigada com águas calcárias, de poços tubulares.

Teores foliares acima da faixa ótima foram observados para P, K e S aos 90, 180 e 360 dias, em todos os sistemas de irrigação, e para $\mathrm{Mg}$ aos 90 dias. Os teores elevados, registrados no presente trabalho, provavelmente, são decorrentes das adubações orgânicas e inorgânicas, efetuadas ao longo do ciclo da cultura, e do histórico de uso da área. Silva \& Rodrigues (2001) encontraram valores acima do ideal para esses nutrientes. Borges et al. (2006) e Damatto Junior et al.
(2006) constataram valores de $\mathrm{Mg}$ e $\mathrm{S}$ acima da faixa ótima, em avaliações de genótipos e de doses de adubo orgânico, respectivamente.

Quanto às diferenças observadas entre os genótipos, independentemente dos sistemas de irrigação, para $\mathrm{N}$ avaliado aos 90 dias após o plantio, $\mathrm{P}$ aos 360 dias, $\mathrm{K}$ aos 180 e 360 dias, $\mathrm{Ca}$ aos 90 dias e para o $\mathrm{Mg}$ nas três épocas (Tabela 3), a 'Prata-Anã' teve valores inferiores de P, aos 360 dias, e de $\mathrm{K}$ aos 180 e 360 dias (Tabela 3). O híbrido PA42-44 teve menores teores de $\mathrm{N}$ e de $\mathrm{Ca}$, aos 90 dias, e de $\mathrm{Mg}$, nas três épocas avaliadas. Esses resultados decorrem da provável diferença na eficiência de absorção de nutrientes entre os genótipos (Faria, 1997; Borges et al., 2006), que pode ocorrer mesmo entre parentais muito próximos, como entre genitora e progênie, e mesmo entre clones (Martin-Prével, 1984).

Os teores foliares de $\mathrm{K}$ aos 180 e 360 dias, em 'Prata-Anã', e os de Ca, aos 90 dias, e os de $\mathrm{Mg}$, em todas as épocas, no híbrido 'PA42-44', estiveram na faixa adequada, ao passo que os teores de $\mathrm{P}$ aos 360 dias, em ambos os genótipos, e os de $\mathrm{N}$ aos 90 dias, no híbrido, estiveram acima do ótimo. Neste trabalho, adicionou-se esterco ao plantio e a cada 60 dias, embora já houvesse histórico de uso, na área, de material orgânico. Isto, provavelmente, contribuiu para o aumento nos teores foliares desses nutrientes, pois cerca de $95 \%$ do $\mathrm{N}$ do solo está associado à matéria orgânica e $50 \%$ do P na biosfera encontra-se em formas orgânicas (Silva \& Mendonça, 2007). Damatto Junior et al. (2006) trabalharam com diferentes doses de composto orgânico em 'Prata-Anã' e obtiveram teores foliares de $\mathrm{N}$ e $\mathrm{P}$ acima da faixa de suficiência.

Diferenças significativas quanto a $\mathrm{Fe}, \mathrm{Mn}$ e $\mathrm{Na}$ foram observadas entre os sistemas de irrigação, independentemente dos genótipos (Tabela 4). Apenas o zinco mostrou similaridade estatística entre os sistemas de irrigação, nas diferentes datas de avaliação. Nos casos significativos, a comparação entre sistemas de irrigação, independentemente dos genótipos, evidencia menores valores para o gotejamento, particularmente aos 360 dias após o plantio. Valores maiores e intermediários em gotejamento, comparado aos demais sistemas de irrigação, foram registrados aos 90 e 180 dias após o plantio. Isto pode ser justificado pelas melhores condições de umidade na zona radicular, propiciadas pelo gotejamento nos primeiros cinco meses de idade da cultura, fase em que as raízes 
encontram-se próximas ao pseudocaule (Costa et al., 2008), e pelas piores condições de umidade aos 360 dias, quando as raízes encontram-se mais distantes.

No que se refere ao Fe, registraram-se diferenças significativas entre microaspersão (menor valor) e aspersão convencional, aos 180 dias (Tabela 4). Para o Mn, registraram-se diferenças significativas entre gotejamento (menor valor) e os demais sistemas, aos 90 dias, e entre gotejamento (menor valor) e aspersão convencional, aos 180 dias após o plantio. Quanto ao $\mathrm{Na}$, o gotejamento diferiu (menor valor) dos demais sistemas de irrigação, aos 90 dias e, aos 180 e 360 dias após o plantio, a aspersão convencional diferiu (maior valor) dos demais sistemas. O transporte do Na ocorre, preferencialmente, por fluxo de massa, e a maior área molhada proporcionada pela aspersão, comparada aos outros sistemas, aumenta o fluxo do elemento no solo até as raízes.

Os genótipos diferiram entre si quanto aos teores foliares de $\mathrm{Mn}$, independentemente dos sistemas de irrigação (Tabela 4). Os menores teores de $\mathrm{Mn}$ ocorreram no híbrido PA42-44, em todas as avaliações. Borges et al. (2006) observaram diferenças significativas entre genótipos, no primeiro ciclo, para $\mathrm{B}, \mathrm{Cu}, \mathrm{Fe}, \mathrm{Mn}$ e $\mathrm{Zn}$ e, no segundo ciclo, para $\mathrm{Cu}, \mathrm{Mn}$ e $\mathrm{Zn}$.
De forma geral, os teores de Fe, Mn e Zn encontramse nas faixas adequadas. Teores acima da faixa foram observados para Zn, nos três sistemas de irrigação e nos dois genótipos, aos 360 dias após o plantio.

Considerando-se todos os micronutrientes, a maior variação nos teores foliares foi exibida por $\mathrm{B}, \mathrm{Na}$ e $\mathrm{Mn}$, e a menor variação por Fe e Zn (Tabela 4). Silva \& Rodrigues (2001) encontraram maior variação nos teores foliares de $\mathrm{Na}, \mathrm{Mn}$ e $\mathrm{Cu}$. Os teores foliares de B, aos 90 e 360 dias após o plantio, expressaram valores abaixo e acima da faixa adequada, respectivamente. Os teores foliares de $\mathrm{Zn}$, aos 90 e 180 dias, tiveram valores dentro da faixa adequada e, aos 360 dias, acima da faixa. As adubações com B (1,7 g por família) e Zn (4,5 g por família), realizadas antes das amostragens foliares, aos 180 dias, e fracionadas aos 300 e 330 dias após o plantio são possíveis explicações para esse resultado. Ainda, a paralisação do crescimento da planta mãe, após o florescimento, pode contribuir para o aumento dos teores foliares de micronutrientes imóveis na planta. Entretanto, Rodrigues et al. (2007) concluíram que doses de $\mathrm{Zn}$ de até $10 \mathrm{~g}$ por família, por ano, alteraram os teores foliares de $\mathrm{Zn}$, porém não o bastante para tirá-los da faixa de suficiência.

No que se refere à produtividade, não houve interação entre genótipos e sistemas de irrigação, e nem efeitos

Tabela 4. Teores foliares médios de micronutrientes $\left(\mathrm{mg} \mathrm{kg}^{-1}\right)$, avaliados aos 90,180 e 360 dias após o plantio, nos genótipos de bananeira 'Prata-Anã' e 'PA42-44', submetidos aos sistemas de irrigação por aspersão convencional, microaspersão e gotejamento $^{(1)}$.

\begin{tabular}{|c|c|c|c|c|c|c|c|}
\hline \multirow[t]{2}{*}{ Micronutriente } & \multirow[t]{2}{*}{ Dias } & \multicolumn{3}{|c|}{ Sistema de irrigação } & \multicolumn{2}{|c|}{ Genótipo } & \multirow[t]{2}{*}{$\mathrm{CV}(\%)$} \\
\hline & & Aspersão & Microaspersão & Gotejamento & 'Prata-Anã' & 'PA42-44' & \\
\hline \multirow{3}{*}{ Boro } & 90 & $6,69 a$ & $5,69 \mathrm{ab}$ & $4,20 \mathrm{~b}$ & $5,64 a$ & $5,42 \mathrm{a}$ & 29,25 \\
\hline & 180 & $20,22 \mathrm{a}$ & $21,02 \mathrm{a}$ & $26,90 \mathrm{a}$ & $22,58 \mathrm{a}$ & $22,84 a$ & 30,00 \\
\hline & 360 & $49,68 \mathrm{a}$ & $47,32 \mathrm{ab}$ & $36,06 \mathrm{~b}$ & $47,38 \mathrm{a}$ & $41,34 \mathrm{a}$ & 23,03 \\
\hline \multirow{3}{*}{ Cobre } & 90 & $7,64 \mathrm{a}$ & $7,23 \mathrm{a}$ & $7,83 \mathrm{a}$ & $7,02 \mathrm{a}$ & $8,10 \mathrm{a}$ & 22,24 \\
\hline & 180 & $6,85 \mathrm{a}$ & $7,07 \mathrm{a}$ & $7,40 \mathrm{a}$ & $6,72 \mathrm{a}$ & $7,49 \mathrm{a}$ & 15,91 \\
\hline & 360 & $8,27 \mathrm{a}$ & $7,42 \mathrm{a}$ & $5,73 b$ & $6,07 \mathrm{~b}$ & $8,21 \mathrm{a}$ & 13,68 \\
\hline \multirow{3}{*}{ Ferro } & 90 & $73,44 a$ & $105,00 \mathrm{a}$ & $82,04 a$ & $86,02 \mathrm{a}$ & $87,64 a$ & 29,95 \\
\hline & 180 & $189,76 a$ & $133,84 b$ & $141,30 \mathrm{ab}$ & $155,28 \mathrm{a}$ & $154,66 \mathrm{a}$ & 24,80 \\
\hline & 360 & $82,61 \mathrm{a}$ & $73,50 \mathrm{a}$ & $99,90 \mathrm{a}$ & $80,85 \mathrm{a}$ & $89,82 \mathrm{a}$ & 49,82 \\
\hline \multirow{3}{*}{ Manganês } & 90 & $202,00 \mathrm{~b}$ & $322,04 a$ & $146,96 \mathrm{~b}$ & $270,03 \mathrm{a}$ & $177,31 b$ & 37,45 \\
\hline & 180 & $313,78 \mathrm{a}$ & $215,40 \mathrm{ab}$ & $163,48 b$ & $279,12 \mathrm{a}$ & $176,53 b$ & 39,62 \\
\hline & 360 & $286,18 \mathrm{a}$ & $308,44 a$ & $231,24 \mathrm{a}$ & $349,52 \mathrm{a}$ & $201,06 b$ & 45,83 \\
\hline \multirow{3}{*}{ Zinco } & 90 & $16,58 \mathrm{a}$ & $15,79 \mathrm{a}$ & $15,74 \mathrm{a}$ & $15,97 \mathrm{a}$ & $17,31 \mathrm{a}$ & 21,19 \\
\hline & 180 & $17,48 \mathrm{a}$ & $17,65 \mathrm{a}$ & $18,24 \mathrm{a}$ & $17,25 \mathrm{a}$ & $18,33 \mathrm{a}$ & 9,85 \\
\hline & 360 & $30,50 \mathrm{a}$ & $34,95 \mathrm{a}$ & $28,60 \mathrm{a}$ & $30,31 \mathrm{a}$ & $32,39 a$ & 44,65 \\
\hline \multirow{3}{*}{ Sódio } & 90 & $46,73 a$ & $56,65 a$ & $23,61 b$ & $47,45 \mathrm{a}$ & $39,20 \mathrm{a}$ & 35,03 \\
\hline & 180 & $95,50 \mathrm{a}$ & $50,48 b$ & $47,47 b$ & $57,20 \mathrm{a}$ & $71,77 \mathrm{a}$ & 33,05 \\
\hline & 360 & $60,80 \mathrm{a}$ & $28,23 b$ & $35,08 \mathrm{~b}$ & $40,92 \mathrm{a}$ & $41,82 \mathrm{a}$ & 40,38 \\
\hline
\end{tabular}

${ }^{(1)}$ Médias seguidas por letras iguais nas linhas, em um mesmo tratamento, não diferem entre si, pelo teste de Tukey, a 5\% de probabilidade. 
significativos isolados de sistemas de irrigação e de genótipos, a $5 \%$ de probabilidade. A produtividade variou de $13,84 \mathrm{Mg} \mathrm{ha}^{-1}$, em PA42-44 sob gotejamento, a $17,53 \mathrm{Mg}$ ha-1 em 'Prata-Anã' sob aspersão. As médias de produtividade dos genótipos foram de $14,92 \mathrm{Mg} \mathrm{ha}^{-1}$ para PA42-44 e de 16,01 $\mathrm{Mg} \mathrm{ha}^{-1}$ para 'Prata-Anã', estatisticamente iguais. Esses valores de produtividade são considerados baixos. O deficit hídrico experimentado pela cultura na fase de florescimento, por problemas operacionais de abastecimento de água, pode justificar esses resultados. Donato et al. (2006, 2009) também constataram similaridade estatística entre a produtividade de 'Prata-Anã' e a de 'PA42-44'. Entretanto, os valores de produtividade observados foram maiores comparados aos do presente trabalho.

Fernandes et al. (2008) avaliaram a 'Prata-Anã', irrigada por gotejamento, com uso de água calcária de poço tubular com salinidade alta e concentração média de sódio, durante dez anos. Embora também classificada como $\mathrm{C}_{3} \mathrm{~S}_{1}$, a água utilizada era de pior qualidade em comparação à do presente trabalho. Esses autores constataram desequilíbrios nutricionais que limitaram a produtividade da bananeira. A produtividade máxima alcançada foi de $18,2 \mathrm{Mg} \mathrm{ha}^{-1}$, no sexto ano de cultivo, inferior à normalmente encontrada na região.

\section{Conclusões}

1. Os genótipos e os sistemas de irrigação por gotejamento, microaspersão e aspersão influenciam o estado nutricional das plantas de bananeira tipo Prata no primeiro ciclo de produção, mas não influenciam a produtividade.

2. A irrigação por gotejamento proporciona os menores teores foliares de micronutrientes em folhas de bananeira tipo Prata no primeiro ciclo de produção, em comparação à irrigação por aspersão e microaspersão.

\section{Referências}

BORGES, A.L.; CALDAS, R.C. Teores de nutrientes nas folhas de bananeira, cv. 'Pacovan', sob irrigação. Ciência e Agrotecnologia, v.28, p.1099-1106, 2004.

BORGES, A.L.; SILVA S. de O. e; CALDAS, C.R.; LEDO, C.A. da $\mathrm{S}$. Teores foliares de nutrientes em genótipos de bananeira. Revista Brasileira de Fruticultura, v.28, p.314-318, 2006.

CANTARUTTI, R.B.; BARROS, N.F.; MARTINEZ, H.E.P.; NOVAIS, R.F. Avaliação da fertilidade do solo e recomendações de fertilizantes. In: NOVAIS, R.F.; ALVAREZ V., V.H.; BARROS,
N.F. de; FONTES, R.L.F.; CANTARUTTI, R.B.; NEVES, J.C.L. (Ed.). Fertilidade do solo. Viçosa: Sociedade Brasileira de Ciência do Solo, 2007. p.769-850.

COELHO, E.F.; OLIVEIRA, S.L.; COSTA, E.L. Irrigação da bananeira. In: SIMPÓSIO NORTE MINEIRO SOBRE A CULTURA DA BANANA, 1., 2001, Nova Porteirinha. Anais. Montes Claros: Unimontes, 2001. p.91-101.

COSTA, E.L.; COELHO. E.F.; SIMÃO, F.R.; FILHO, M.A.C.; OLIVEIRA, P.M. Irrigação da bananeira. Informe Agropecuário, v.29, p.38-46, 2008.

DAMATTO JUNIOR, E.R.; VILLAS BÔAS, R.L.; LEONEL, S.; FERNANDES, D.M. Avaliação nutricional em folhas de bananeira 'Prata' Anã' adubadas com composto orgânico. Revista Brasileira de Fruticultura, v.28, p.109-112, 2006.

DONATO, S.L.R.; ARANTES, A. de M.; SILVA, S. de O. e; CORDEIRO, Z.J.M. Comportamento fitotécnico da bananeira 'Prata-Anã' e de seus híbridos. Pesquisa Agropecuária Brasileira, v.44, p.1608-1615, 2009.

DONATO, S.L.R.; SILVA, S. de O. e; LUCCA FILHO, O.A.; LIMA, M.B.; DOMINGUES, H.; ALVES, J. da S. Comportamento de variedades e híbridos de bananeira (Musa spp.), em dois ciclos de produção no sudoeste da Bahia. Revista Brasileira de Fruticultura, v.28, p.139-144, 2006.

FARIA, N.G. Absorção de nutrientes por variedades e híbridos promissores de bananeira. 1997. 66p. Dissertação (Mestrado) Universidade Federal da Bahia, Cruz das Almas.

FERNANDES, L.A.; RAMOS, S.J.; VALADARES, S.V.; LOPES, P.S.N.; FAQUI, V. Fertilidade do solo, nutrição mineral e produtividade da bananeira irrigada por dez anos. Pesquisa Agropecuária Brasileira, v.43, p.1575-1581, 2008.

MALAVOLTA, E.; VITTI, G.C.; OLIVEIRA, S.A. de. Avaliação do estado nutricional das plantas: princípios e aplicações. 2.ed. Piracicaba: Associação Brasileira para Pesquisa da Potassa e do Fosfato, 1997. 319p.

MALBURG, J.L. Métodos de amostragem foliar para a diagnose nutricional da bananeira 'Enxerto' ('Prata' Anã') no sul de Santa Catarina. 1988. 94p. Dissertação (Mestrado) - Escola Superior de Agricultura de Lavras, Lavras.

MARTIN-PRÉVEL, P. Échantillonnage du bananier pour l'analyse foliaire: conséquenses des différences de techniques. Fruits, v.32, p.151-166, 1977.

MARTIN-PRÉVEL, P. Exigências nutricionais da bananicultura. In: SIMPÓSIO BRASILEIRO SOBRE BANANICULTURA, 1., 1984, Jaboticabal. Anais. Jaboticabal UNESP: FCAV, 1984. p.118-134.

NOVAIS, R.F.; MELLO, J.W.V. Relação solo-planta. In: NOVAIS, R.F.; ALVAREZ V., V.H.; BARROS, N.F. de; FONTES, R.L.F.; CANTARUTTI, R.B.; NEVES, J.C.L. (Ed.). Fertilidade do solo. Viçosa: Sociedade Brasileira de Ciência do Solo, 2007. p.133-204.

PREZOTTI, L.C. Recomendações de calagem e adubação para o Estado do Espírito Santo: $3^{\mathrm{a}}$ aproximação. Vitória: EMCAPA, 1992. 73p. (Circular técnica, 12). 
RODRIGUES, M.G.V.; DIAS, M.S.C.; RUGGIERO, C.; LICHTEMBERG, L.A. Planejamento, implantação e manejo do bananal. Informe Agropecuário, v.29, p.14-24, 2008.

RODRIGUES, M.G.V.; RUGGIERO, C.; NATALE, W.; PACHECO, D.D. Nutrição e produção da bananeira 'Prata-Anã' adubada com zinco e boro diretamente no rizoma, via muda desbastada. Revista Brasileira de Fruticultura, v.29, p.645-651, 2007.

RUFYIKIRI, G.; DUFEY, J.E.; ACHARD, R.; DELVAUX, B. Cation exchange capacity and aluminum-calcium-magnesium binding in roots of bananas (Musa spp.) cultivated in soils and in nutrient solutions. Communications in Soil Science and Plant Analysis, v.33, p.991-1009, 2002.

SILVA, A.J.P. da; COELHO, E.F.; MIRANDA, J.H. de; WORKMAN, S.R. Estimating water application efficiency for drip irrigation emitter patterns on banana. Pesquisa Agropecuária Brasileira, v.44, p.730-737, 2009.

SILVA, E. de B.; RODRIGUES, M.G.V. Levantamento nutricional dos bananais da Região Norte de Minas Gerais pela análise foliar. Revista Brasileira de Fruticultura, v.23, p.695-698, 2001.

SILVA, J.T.A. da; BORGES, A.L. Solo, nutrição mineral e adubação da bananeira. Informe Agropecuário, v.29, p.25-37, 2008.
SILVA, J.T.A. da; BORGES, A.L.; DIAS, M.S.C.; COSTA, E.L. da; PRUDÊNCIO, J.M. Diagnóstico nutricional da bananeira 'Prata' Anã' para o norte de Minas Gerais. Belo Horizonte: EPAMIG, 2002. 16p. (EPAMIG. Boletim técnico, 70).

SILVA, J.T.A. da; BORGES, A.L.; MALBURG, J.L. Solos, adubação e nutrição da bananeira. Informe Agropecuário, v.20, p.21-36, 1999.

SILVA, J.T.A. da; CARVALHO, J.G. de. Avaliação nutricional de bananeira 'Prata'-Anã' (AAB), sob irrigação no semi-árido do norte de Minas Gerais, pelo método DRIS. Ciência e Agrotecnologia, v.29, p.731-739, 2005.

SILVA, R.I.; MENDONÇA, E. Matéria orgânica do solo. In: NOVAIS, R.F.; ALVAREZ V., V.H.; BARROS, N.F. de; FONTES, R.L.F.; CANTARUTTI, R.B.; NEVES, J.C.L. (Ed.). Fertilidade do solo. Viçosa: Sociedade Brasileira de Ciência do Solo, 2007. p.338-341.

SILVA, S. de O. e; FLORES, J.C. de O.; LIMA NETO, F.P. Avaliação de cultivares e híbridos de bananeira em quatro ciclos de produção. Pesquisa Agropecuária Brasileira, v.37, p.1567-1574, 2002.

Recebido em 5 de maio de 2010 e aprovado em 2 de agosto de 2010 